\title{
Promoting Excellence in Rehabilitation Research
}

This is the 10th volume of the journal, effectively marking its 10 -year history of contributing to scholarly debate and informing best practice in rehabilitation research and applied service delivery. I am pleased to have been associated with the journal for that entire period and remain firmly convinced that the research output from the journal ranks with the best on offer in the international academic environment. That tradition of excellence continues with the contributions to this issue of the journal. Lucinda Allison and Christine Stephens provide an insightful analysis of the role of pain beliefs in predicting recovery from RSI and their findings underscore the complexity of that relationship. Maureen Dillon and her colleagues present an intriguing analysis of the phenomenology of a multidisciplinary health care team, and the dynamics of such a team are unpacked in interesting ways via the use of tape transcript data. Cheryl Gilbert and Ian Hay present a quasi-experimental design involving a sample with an acquired physical or psychological disability plus a history of long. term unemployment. The effectiveness of their intervention program in terms of employment outcomes is clearly very positive. Peter Mcllveen and his colleagues outline the development and positive effects of a career forum for university students with a disability contemplating the study-to-work transition. Christine Roberts-Yates continues some of the themes she has developed in previous contributions to the journal and looks at the notion of a learning partnership among the stakeholders involved in the workplace claims/injury management process.

Congratulations to all contributors for the diversity of their papers and the consistent high standard of scholarship that is clearly evident in their work.

Some minor points of editorial housekeeping. Despite the best of intentions (and signalling thus in the last issue of the journal) I have yet to update the list of consulting editors on the front inside cover of the journal. As I said last time, if there is anyone within the diverse constituency that makes up the readership of this journal who would like to take on this role then please let me know (my contact details are on the inside back cover). Peer review is important, and is a difficult process to maintain. Busy professionals who are asked to peer review a journal article often have to shift that task down the priority queue when more pressing and urgent professional concerns are knocking at the door. The timely production of the journal depends in part on the goodwill and patience of peer reviewers. So I would certainly encourage anyone who has an interest (and the background research credentials) to nominate themselves for this role.

Can I again draw attention to the guidelines for authors on the inside back cover - these were changed for issue 9.1 and are intended to apply henceforth. It would be helpful if potential contributors could take a look at these as there is often considerable editorial time taken up with reformatting articles to appropriate APA standards.

Thank you to the AJRC journal subscribers for their continued patient support of the journal (despite its often tardy arrival in the mail).

Ross Flett, PhD, Editor 
